\title{
VEGETAÇÃO E QUINTAIS DA CASA BRASILEIRA
}

\section{Guilherme Mazza Dourado}

Arquiteto e pesquisador, mestre pelo Departamento de Arquitetura e Urbanismo da EESC/USP. É autor dos livros Modernidade verde. Jardins de Burle Marx (São Paulo: Edusp, no prelo) e Visões de paisagem. Um panorama do paisagismo contemporâneo no Brasil (São Paulo: ABAP, 1997); co-autor do volume Oswaldo Arthur Bratke (São Paulo: Pró-Editores, 1997); colaborador no livro Luoghi. Forma e Vita di Giardini e di Paesaggi (Treviso: Edizioni Fondazione Benettton Studi Ricerche/ Canova, 2001).

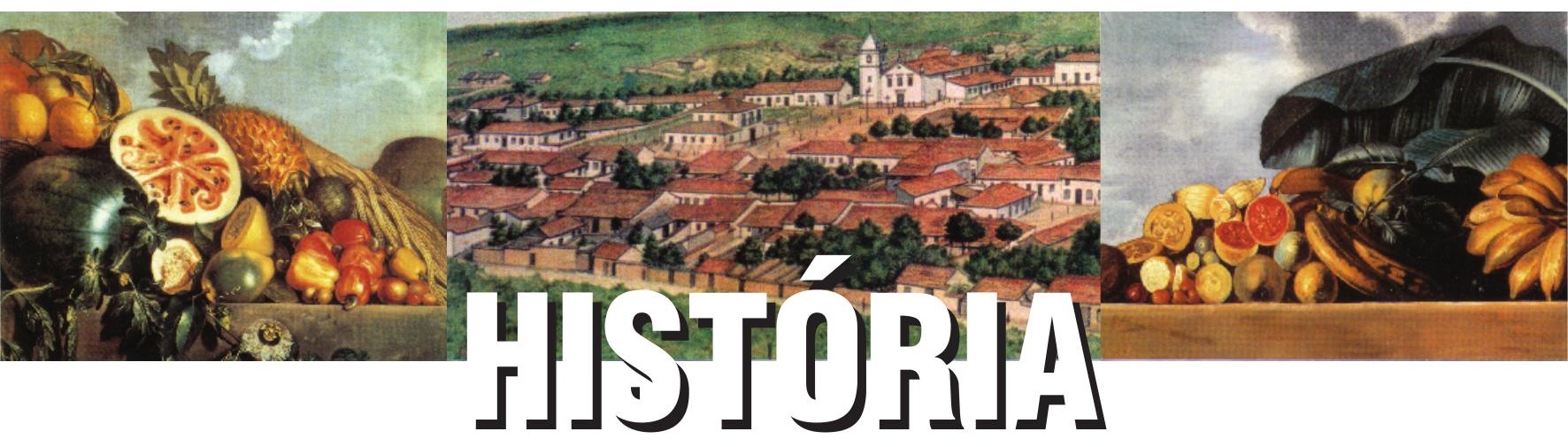




\title{
RESUMO
}

Não há como entender as transformações da paisagem natural no Brasil colonial, sem considerar o papel dos quintais domésticos enquanto centros de experimentação e difusão de plantas exóticas e autóctones. Nem tão pouco é possível rastrear a formação dos primeiros espaços verdes das cidades coloniais, sem considerar os quintais das residências. Este artigo alinhava uma introdução à história dos quintais brasileiros e sua vegetação, entre os séculos 16 e 18. Investiga os múltiplos significados e atributos que eles desempenharam no cotidiano doméstico, mapeando, principalmente, algumas das plantas alimentares mais cultivadas neles. Destaca a ação dos portugueses tanto na introdução de espécies exóticas, como laranjeiras, bananeiras, mamoeiros, jaqueiras, mangueiras, quanto no aproveitamento de essências nacionais, caso dos cajueiros, mangabeiras, goiabeiras, maracujazeiros.

Palavras-chave: Quintais domésticos, vegetação no Brasil colonial, plantas alimentares brasileiras e exóticas, aclimatação e difusão de espécies orientais, história das plantas.

\begin{abstract}
To understand the changes in the natural landscape of colonial Brazil one must first consider the role played by domestic backyards as centres of experimentation and in the diffusion of exotic and native plants. The study of residential backyards is also indispensable to tracing the formation of the first green areas in colonial cities. This article outlines an introduction to the history of brazilian backyards and their vegetation, from the $16^{\text {th }}$ to the $18^{\text {th }}$ centuries. It investigates the multiple meanings held by them and their attributes in daily domestic life, principally mapping some of the food plants cultivated in them. It emphasizes the action of the portuguese in both the introduction of exotic species, such as the orange, banana, papaya, jackfruit and mango, and the use of native species such as cashew, mangabeira, guava and passion fruit.
\end{abstract}

Key words: Domestic backyards, vegetation in colonial Brazil, brazilian and exotic food plants, acclimatization and spread of oriental species, history of the plants. 


\section{VEGETAÇÃO E QUINTAIS DA CASA BRASILEIRA}

Se existiram ambientes imprescindíveis no Brasil colonial, foram os quintais. Extensões orgânicas da casa rural e urbana, eles foram palco de boa parte das atividades cotidianas e despensa que garantiu a subsistência familiar, em uma época na qual, de modo geral, havia precárias redes de produção e comércio de alimentos. No campo, funcionaram como balão-de-ensaio da agricultura trazida pelo colonizador. Na cidade, formalizam os primeiros espaços verdes, bem antes da constituição de passeios e parques públicos. Neste estudo, vamos alinhavar uma introdução à história dos quintais brasileiros entre os séculos 16 e 18, destacando, principalmente, algumas das espécies arbóreas e arbustivas mais cultivadas, responsáveis pelo fornecimento de alimentos.

Figura 1:

Quintais domésticos repletos de vegetação em Vila do Bom Jesus de

Cuiabá. Detalhe da aquarela pertencente ao Arquivo Histórico do Museu Bocage,

Universidade de Lisboa

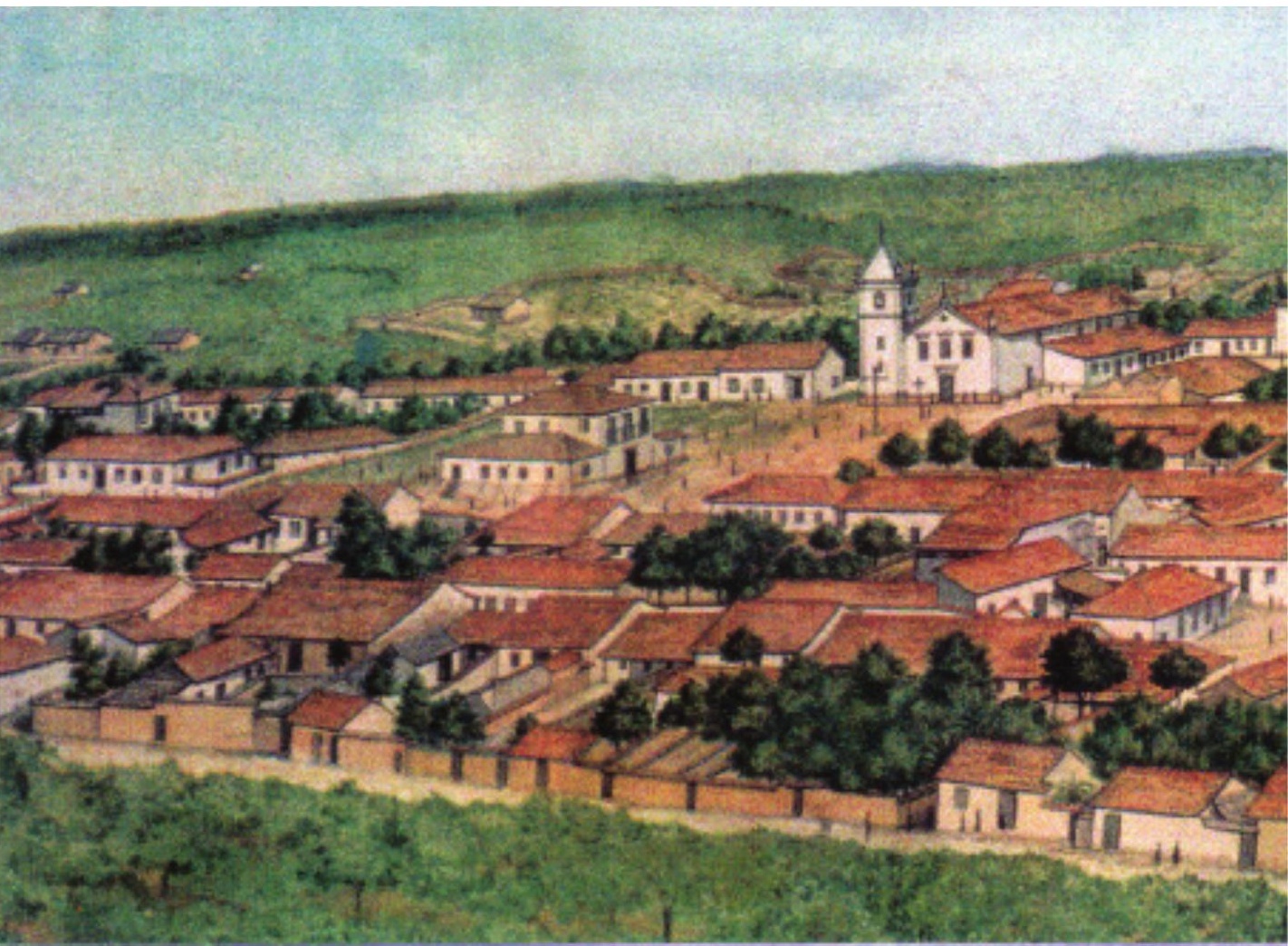




\section{Significados e Atributos}

Todo bom dicionário de português traz um verbete sobre quintal. Provendo de quintanale, do latim vulgar, a palavra designa uma pequena quinta ou pequena área cultivada junto à habitação. Houaiss e Salles (2003, p. 2.364) registram que quintal é "terreno geralmente com jardim ou horta, atrás de uma casa de moradia ou junto a ela". Complementam que, na região do Algarve, é sinônimo de "pequeno terreno com estrumeira" e, no Brasil, pode significar também pátio cimentado na casa.

Relacionados proximamente ao termo, estão as palavras quinta e quintalão. Quinta é propriedade agrícola rural, chácara e também indica pomar de laranjeiras, nos Açores. Já quintalão é um grande quintal e, no Algarve, denomina o terreno cercado para serviços domésticos.

Os dicionários de arquitetura fornecem mais algumas informações. Corona e Lemos (1972, p. 397) assinalam que quintal é "terreno cultivado ou não, anexo a uma residência urbana ou rural, servindo de pátio, terreiro, jardim, horta e pomar". Destacam que, nas moradias urbanas, acabaram por nomear apenas as áreas livres posteriores ou nos fundos. Portanto, quintal é espaço com múltiplos significados e atributos no cotidiano doméstico. Pode ser apenas um simples vazio para o qual se volta a habitação ou ambiente vivo e dinâmico na rotina da casa. Pode harmonizar tanto as atividades relacionadas à manutenção da vida familiar, como o cultivo de espécies frutíferas, verduras e legumes, quanto as funções derivadas do puro prazer, como o plantio de espécies ornamentais e flores.

\section{Coração da Vida}

No período colonial, o quintal nasceu simultaneamente com a casa brasileira e tornou-se parte inseparável dela. Foi trazido pelos portugueses e sofreu miscigenação, do mesmo modo que o colono, somando influências indígenas e africanas. Foi espaço aberto sempre presente na habitação de ricos e pobres, na moradia urbana e rural, mas tinha algumas particularidades. Afora extensão variável e também variável número de construções de serviço e cultivos que reunia, o quintal apresentava dois tipos básicos em praticamente todas as regiões brasileiras. Na versão urbana, figurava sempre nos fundos, protegido no interior dos quarteirões. No modelo rural, envolvia geralmente a casa, criando um espaço de transição entre o edifício e as terras agricultáveis ou paisagens, nos arredores.

86 Entre os séculos 16 e 18, o quintal foi o coração da vida doméstica. Nele havia e fazia-se de tudo, a começar pela cozinha, disposta sob suas árvores ou telheiro. Era espaço para lavagem e secagem de roupas, tingimento de fios para tecidos, produção da farinha de mandioca, beneficiamento de ce- 


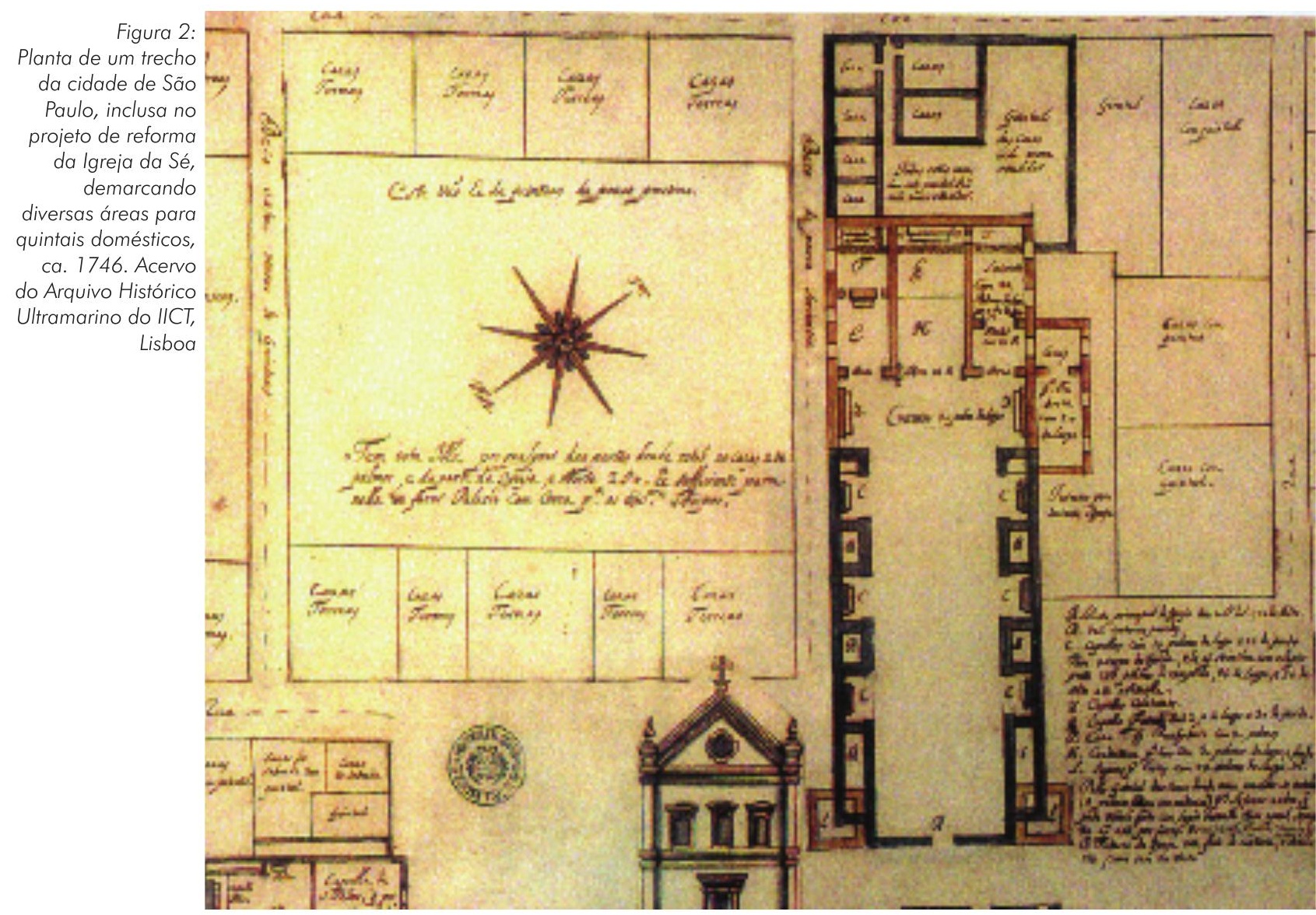

reais, para as hortas e pomares, criação de animais, brincadeira da criançada, para a sesta, para contar estórias, ouvir cantorias, para fazer festas à noite e muito mais (cf. LEMOS, 1976).

$\mathrm{Na}$ casa rural paulista, o quintal chegou a ter características próprias, em certos casos. Assinala Lemos (1976, p. 67) que "algumas vezes, na frente ele se transformava em jardim de flores, mas, na maioria dos casos, a parte fronteira constituía um grande terreiro de terra limpa e varrida, onde se malhava o feijão, se secava o café e onde se dançava nas noites de festa. Os quintais roceiros de São Paulo eram cercados de muros de taipa, com vedos de varas ou moirões grossos de arueira, madeira boa para ficar chumbada no chão. Dentro destas cercas, toda sorte de plantas e árvores".

Já nas moradas das vilas de São Paulo, o papel do quintal não variava, substancialmente, em relação ao congênere do campo. Lemos (1976, p. 69) comenta que "eram menores, porém ofereciam também bastante mantimento, principalmente bananas, e davam pouso para as criações domésticas. E também neles, sempre, construções avulsas, isoladas, ao longo dos muros, servindo de depósito, despensas, galinheiro, privada, quarto para escravos e de cozinha". 


\section{Bens Familiares}

Do Norte ao Sul do Brasil, o quadro de usos e funções não se modificava, fundamentalmente, na época. Como também não se alterava, significativamente, a importância atribuída aos quintais como bens familiares preciosos. Com freqüência, eram mencionados em testamentos, inventários, partilhas, escrituras de compra e venda, doações e mesmo em peças jurídicas excepcionais, como os processos de confisco. Esse foi o caso dos quintais do ilustre poeta Cláudio Manoel da Costa, listados nos Autos da Devassa da Inconfidência Mineira, no final do século 18. O documento registrava a apreensão de "morada de casas com seu quintal cercado de pedra e dentro do mesmo com suas árvores de espinho, casas cobertas com telhas, com quintal e bananal" (apud ALGRANTI, 1997, p. 92).

Da mesma época, mas em uma situação bem mais rotineira, é o inventário de Caetano Miguel da Costa, que deixou aos herdeiros seu rico quintal e demais bens no arraial do Tejuco, Minas Gerais. Tratava-se de "huma morada de casas na rua que sai para a estrada que vai para a Villa do Príncipe, defronte do quartel militar, coberta de telha, com seu quintal coberto de taipa com pátio cercado e engenho com água dentro, árvores de espinho e umas outras frutas" (apud MENESES, 2000, p. 190).

Também nas Minas Gerais setecentista, Caetano José da Costa legava uma típica propriedade rural daquele tempo, com quintal cercado e muito bem cultivado. Seu inventário discriminava (apud MENESES, 2000, p. 193) "hua fazenda denominada Carapixo que se compõe de terras de Cultura em Capoeira e algum Mato Virgem casa de vivenda, terreiro, Payol, Moinho, engenho de Piloens de fazer farinha, engenho de fazer farinha de Mandioca, com casa de alpendre com sua Capela de dizer Missa, tudo coberto de telha, Monjolo e Senzalla de Telha, Curral cercado de raxas de Braúna, quintal cercado das mesmas, Bananal e um grande pomar de Árvores de Espinho e Jabuticabeiras".

\section{Itens Valiosos}

Nos tantos documentos jurídicos do período, havia uma evidente preocupação de registrar e discriminar os elementos que qualificam o quintal, porquanto lhe atribuíam mais valor, constando, geralmente, as árvores frutíferas cultivadas e, em alguns casos, até o número de seus exemplares. Em 1648, o inventário de Rafael de Oliveira continha a descrição de um típico quintal de sítio, no interior paulista. Nele havia (apud LEMOS, 1999, p. 36): "uma casa de dois lanços coberta de telha de taipa de mão com seus corredores e um lanço que serve de despensa e seu galinheiro e casa de trapiche coberta de telha e um pedaço de vinha e uma parreira e um pedaço de canavial com marmeleiros e bananal limoeiros laranjeiras e mais árvores tudo em sua avaliação de cincoenta e cinco mil reis". 
Anos mais tarde, a mesma propriedade passava por nova transmissão, constando do espólio de Catarina Figueiredo de Horta, viúva de Oliveira. Nesse momento, o quintal dispunha de "árvores de espinho e outras frutas e mandioca" (apud LEMOS, 1999, p. 360).

A partir dessas informações, pode-se extrair uma constante: não havia uma seleção específica de plantas para o quintal urbano e outra para o rural, mas uma única gama de espécies recorrentes e mais difundidas, com porte e procedência variáveis, reunindo vegetação autóctone e/ou exótica introduzida, sobretudo, pelos portugueses. Esse é o caso dos espinheiros, designação genérica da época para laranjeiras, limoeiros e cidras, e também das videiras, marmeleiros e bananeiras. Já a mandioca e jabuticabeiras eram brasileiras.

\section{Trânsito de Plantas}

Os descobrimentos marítimos foram diretamente responsáveis pelo primeiro grande trânsito intercontinental de plantas que a humanidade conheceu. Ávidos por encontrar novas fontes de riqueza vegetal e assegurar o monopólio sobre espécies conhecidas e valorizadas no mercado europeu, os portugueses trataram de estabelecer e multiplicar as trocas de plantas úteis entre suas colônias no Oriente e no Ocidente. Em meados do século 16, começaram a enviar para o Brasil sementes e mudanças de hortaliças e cereais do Reino, de plantas frutíferas do Mediterrâneo e Ásia e das famosas especiarias do Oriente. Por outro lado, trataram de investigar o que estava disponível em terras brasileiras. Esse processo não foi rápido nem simples. Em geral, a transferência vegetal não aconteceu diretamente entre as colônias. Mas foi intermediada por três centros principais de aclimatação e multiplicação vegetal para os domínios portugueses: as ilhas da Madeira e Açores e Cabo Verde (cf. ALMEIDA, 1975; FERRÃO, 1993).

Chegando ao Brasil, as mudas e sementes que resistiam à penosa viagem marítima eram confiadas aos colonos e irmandades em várias regiões, que tratavam de averiguar e informar suas potencialidades de uso ou não à metrópole. Assim, provavelmente, diversas espécies exóticas ganharam os quintais domésticos e, deles, seguiram para lavouras e plantações em escala. $\bigcirc$ papel das ordens religiosas nesse processo ainda está para ser estudado. Deve ter sido muito importante, considerando as informações preliminares que encontramos.

No século 17, os jesuítas mantiveram um centro de pesquisas agrícolas na Quinta do Tanque, Bahia, cultivando espécies das Américas, Europa e Ásia. Nesse local, plantavam canela e pimenta-do-reino. E, dele, partiv, em 1688, remessas de mudas de canela para os colégios da ordem no Maranhão e 
Pará. $\bigcirc$ êxito e a fama dos jesuítas no cultivo das drogas orientais chegaram a tal ponto que as autoridades reais recomendaram que os interessados pedissem sementes diretamente aos reitores da Companhia de Jesus (LAPA, 1966, p. 34-6). Na difusão botânica, essas propriedades jesuítas e de outras congregações foram precursoras dos jardins botânicos no Brasil.

\section{Primeiras Espécies}

Antes disso, dois jesuítas escreveram os primeiros relatos sobre as plantas alimentares utilizadas no Brasil, que figuravam nos quintais domésticos. Em 1549, o padre Manoel da Nóbrega (1517-70) informava aos irmãos portugueses sobre alguns itens da dieta local, sendo cinco introduzidos pelos lusitanos (uvas, laranjas, limões, cidras, figos) e um único nativo, mas que, pela novidade, mereceu mais atenção (mandioca). Registrava em carta (apud HOEHNE, 1937, p. 90): "Há diversas fructas que os da terra comem, ainda que não sejam tão boas como as dela, as quaes também creio se dariam cá, si as plantasse, porque vejo que dão uvas, e até duas vezes ao ano, porém são poucas devido as formigas, que lhes fazem damnos, assim como os fazem também as outras plantas, como sejam: cidras, laranjas, limões, que dão em quantidade e figos tão bons como os de lá. O mantimento commum da terra é uma raiz de pão, que denominam: mandioca, da qual fazem uma farinha

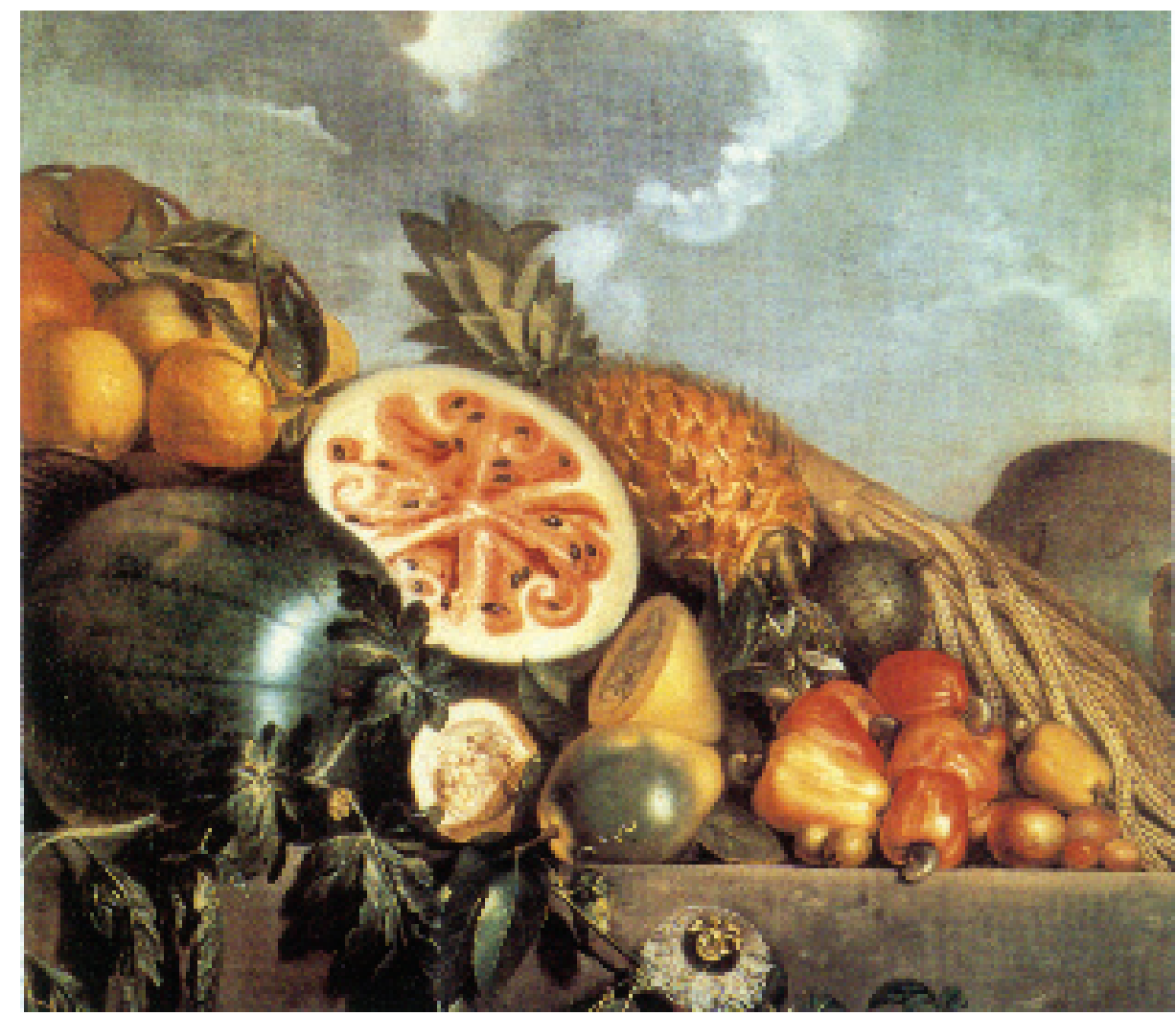

Figura 3:

Abacaxis, cajus, cocos, melancias, laranjas, maracujás: os frutos do quintal alimentavam a família brasileira. Natureza-morta de Albert Eckhout, século 17. Acervo do Nationalmuseet, Copenhague 
de que comem todos, e dá egualmente bom vinho, o qual misturado com a farinha faz um pão que escusa o de trigo."

Em 1585, o padre José de Anchieta (1534-97) acrescentava mais detalhes sobre as plantas úteis em sua Informação da Província do Brasil aos Nossos Padres, buscando conceder idéia de forma, cor e sabor dos alimentos desconhecidos que vicejavam pelos quintais, hortas e pomares, em São Paulo. Sobre os frutos, comentou (apud HOEHNE, 1937, p. 106): "Nesta terra se dão bem arvoredos de espinho, que vieram de Portugal, como laranjeiras, cidreiras, limoeiros, limeiras e todo o anno têm fructos bons sem ser regados; porque o céo tem este cuidado e é a terra tão fértil destas arvores que se dão pelos montes e campos sem beneficio que se lhes faça. Da terra há muitos fructos e alguns de preço e que não dão vantagem às pêras melacoteres de Portugal, mangabas (Hancornia speciosa GOMES) que são como albicorques marellos, não têm caroço sinão umas pevides pequenas e são de bom gosto e mui sadias; mocujês (Couma rigida, MUELL. ARG.) que são como pêros bravos de Portugal, mas de grande gosto e preço e ao comer se sorvem como srovas; acajús (Anacardium occidentale L.) que são como pêros repinaldos e dão uma castanha no olho, melhor que as de Portugal; aracaticús (Rollinia exalbida, MART.) é árvore como limoeiro, o fructo como pinha."

Mais encantado com as novidades da terra do que Nóbrega, Anchieta reservou bom trecho de seu comentário a uma fruta que muito agradou aos estrangeiros e tornou-se presença freqüente nos quintais da época. Era o naná, nome indígena do abacaxi (Ananas commosus L.), o qual, em suas palavras, (apud HOEHNE, 1937, p. 106): "dão-se em uns como cardos e as folhas como herva babosa, o fructo é à moda de pinha, ainda que maior, dão-se todo o anno, é fructo de muito preço e realmente sabem e cheiram a melões, mas são melhores e muito mais odoríferos e têm muito summo, são bons para quem tem dor de pedra. (...) Estes fructos dão nas hortas e pelos campos e bosques em grande abundancia e delles se fazem conservas (...) e não faltam aos nossos como antepasto".

Anchieta assinalou também a existência de legumes e verduras trazidas de Portugal, como as couves, alfaces, pepinos, ervilhas e lentilhas. Em Pernambuco e Rio de Janeiro, dava conta da presença de melões nativos. E falava ainda da introdução de abóboras e favas da Guiné (cf. HOEHNE, 1937, p. 107).

\section{Fruteiras Populares}

A série de espécies alimentares em uso nos quintais domésticos da colônia não parou por aí. Em sua História da Província de Santa Cruz, publicada em 1576 e considerada o primeiro relato histórico de fôlego sobre o Brasil, Pero de Magalhães de Gandavo trazia notícias de outras plantas que muito contribuíam para o sustento diário familiar, como as bananeiras e os cajueiros. 


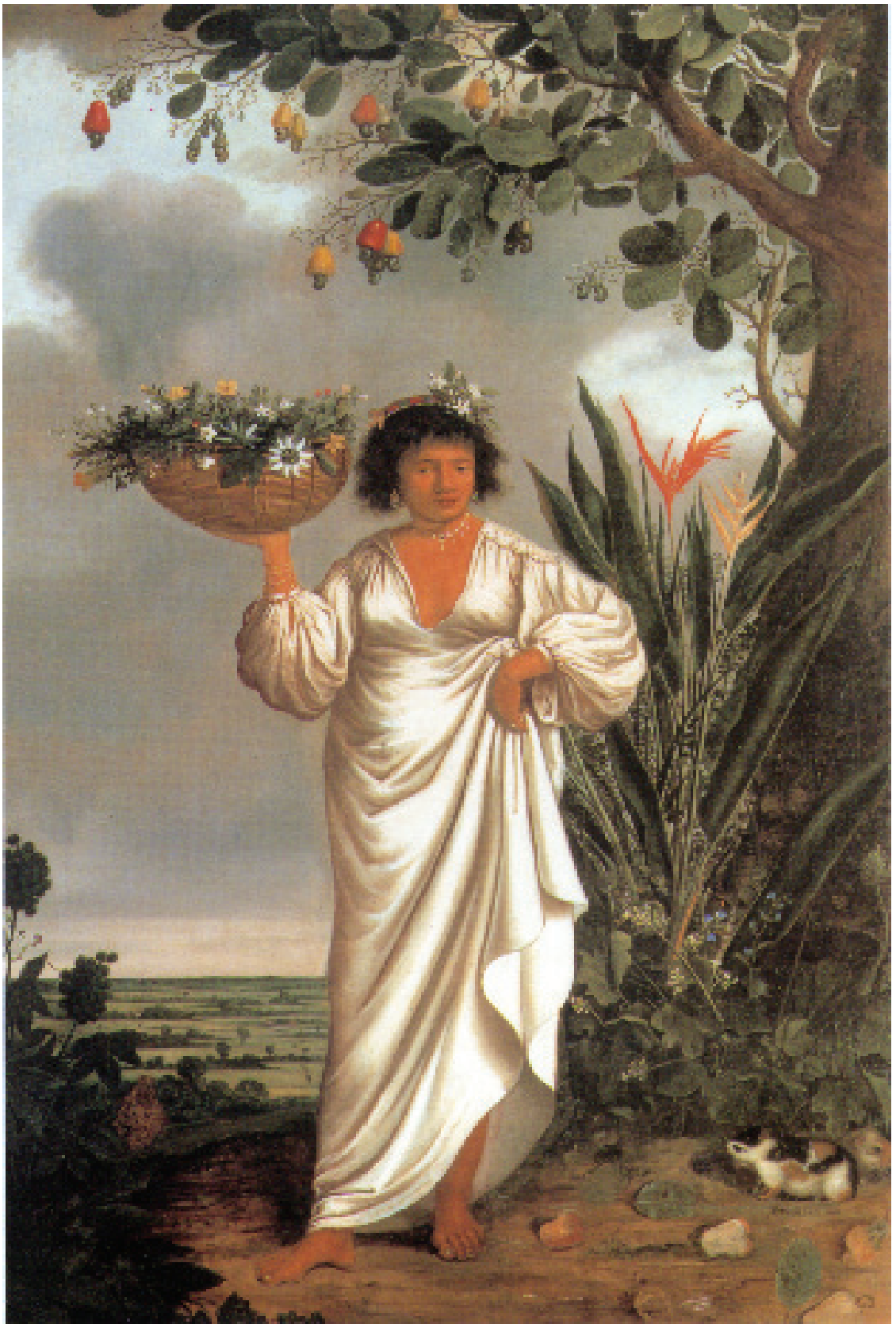

Figura 4:

O cajueiro era uma das fruteiras típicas nos quintais nordestinos. Arvore à direita, na tela Mulher Mameluca, Albert Eckhout, 1641.

Acervo do Nationalmuseet,

Copenhague

Originárias do sudeste da Ásia, diversas variedades de bananeiras já eram conhecidas no Mediterrâneo e África Oriental, bem antes dos descobrimentos. Os portugueses aclimataram-nas em São Tomé e Cabo Verde, distribuindo-as, a seguir, para grande parte de suas colônias. $\bigcirc$ Brasil recebeu, principalmente, mudas de São Tomé, que se popularizaram paulatinamente nos quintais e na agricultura (cf. FERRÃO, 1993). Em uma narrativa pormenorizada, Gandavo informava que (apud HOEHNE, 1937, p. 167): "a planta se dá também nesta Província [Bahia], que foy da Ilha de Sam Thomé, com 
a fructa da qual se ajudam muitas pessoas a sustentar na terra. Esta planta he muy tenra e nam muito alta, nam tem ramos senam humas folhas que serão seis ou sete palmos de comprido. A fruitas dela se chamam bananas: parecemse na feição com pepinos, e criamse em cachos: alguns delles há tan grandes que tem cento e cincoenta bananas para cima, e muitas vezes he tamanho o pezo dellas que acontece quebrar a planta pelo meio. Como sam de vez colhem estes cachos, e dali a alguns dias amadurecem. Depois de colhidos cortam esta planta porque nam frutifica mais que a primeira vez: mas tornam logo a ancer della huns filhos que brotam do mesmo pé, de que se fazem outros emelhantes. Esta futia he mui saborosa, e das boas, que há na terra: tem huma pelle como figo (ainda que mais dura) a qual the lançam fora quando a querem comer, mas faz damno a saúde e causa febre a quem se desmanda nella".

Nativos da faixa litorânea do Nordeste do Brasil, os cajueiros eram muito apreciados pelos índios brasileiros e, por meio deles, os portugueses conheceram a espécie. Entre os séculos 16 e 18, tornou-se árvore freqüente nos quintais de regiões quentes da colônia. E, na mesma época, ganhou o mundo, sendo difundido pelos lusitanos em Cabo Verde, África Oriental, Madagáscar e Ásia. Gandavo ressaltava o papel de seu fruto como uma das maravilhas naturais da terra (apud HOEHNE, 1937, p. 169): "Fruita que nace pelo mato em humas arvores tamanhas como pereiras, ou macieiras: a qual he de feição de pêros repinaldos, e muito amarella. A esta fruita chamam Cajus: tem muito çumo, e comese pela calma pêra refrescar, porque he ella de sua natureza muito fria, e de maravilha não faz mal ainda que se desmandem nella. $\mathrm{Na}$ ponta de cada pomo destes se cria um caroço tamanho como castanhas, da feição de fava: o qual nace primeiro, e vem diante da mesma fruita como flor; a casca delle he muito amargosa em extremo, e o sei meolo asado he muito quente de sua propriedade e nais gostozo que a amêndoa."

\section{Exóticas e Nativas}

De certo, uma da melhores fontes para se averiguar o que mais havia nos quintais brasileiros quinhentistas é o Tratado Descritivo do Brasil em 1587. Nesse estudo, Gabriel Soares de Sousa (c. 1540-91) apresenta uma das mais completas listagens da vegetação útil, de origem exótica ou nativa, disponível na América portuguesa. Informa que na Bahia havia romanzeiras, coqueiros, mamoeiros, mangabeiras, araçazeiros, entre outras árvores frutíferas.

Trazidas da Europa pelos portugueses, as romanzeiras são descritas por Sousa como plantas que vingam "de quaisquer raminhos, os quais pegam e logo dão fruto aos dois anos: as árvores não são nunca grandes, mas dão romã em todo o ano, e não lhes cai nunca a folha de todo; o fruto delas é maravilhoso no gosto e de bom tamanho" (SOUSA, 2000, p. 128). 


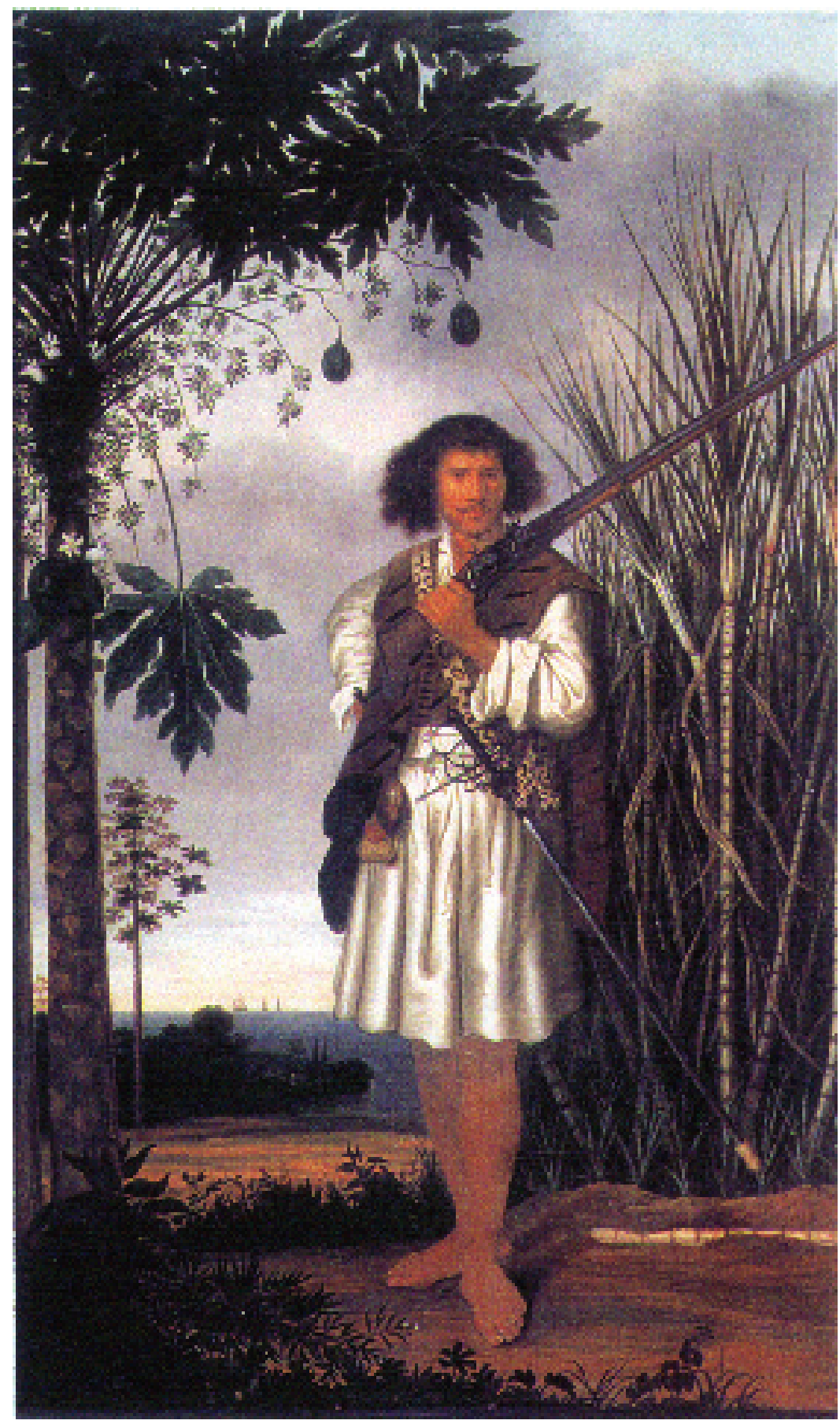

Figura 5:

O mamoeiro era freqüente nos quintais domésticos da faixa tropical brasileira. À esquerda, na tela Homem Mulato, Albert Eckhout, 1643. Acervo do Nationalmuseet, Copenhague

Também introduzidos pelos lusitanos, os coqueiros são originários da Polinésia e sudeste asiático, tendo se dispersado por toda Ásia e África muito antes das grandes navegações. Em sua primeira viagem à Índia, Vasco da Gama os encontrou em Moçambique. Em 1545, iá estavam plantados em Cabo Verde (FERRÃO, 1993, p. 174-6). E desse local partiram os primeiros cocos semeados na Bahia, segundo Sousa (2000, p. 129). 
Os mamoeiros foram outra espécie aclimatada pelos portugueses, originária, possivelmente, da região dos Andes. Chegaram ao Brasil no último quartel do século 16 (FERRÃO, 1993, p. 122). Sousa (2000, p. 150-10) assinala que "De Pernambuco veio à Bahia a semente de uma fruta a que chamam mamões; os quais são do tamanho e da feição e cor de grandes pêros camoeses, e têm muito bom cheiro como são de vez, que se fazem nas árvores, e em casa acabam de amadurecer; e como são maduros se fazem moles como melão; e para se comerem cortam-se em talhadas como maça, e tiram-lhes as pevides que têm envoltas em tiras como as de melão, mas são crespas e pretas como grãos de pimenta da Índia, às quais talhadas se apara a casca, como a maça, e o que se come é da cor e brandura do melão, o sabor é doce e muito gostoso. Estas sementes se semearam na Bahia, e nasceram logo; e tal agasalhado the fez a terra que no primeiro ano se fizeram as árvores mais altas que um homem, e ao segundo começaram a dar fruto, e se fizeram as árvores de mais de vinte palmos de alto, e pelo pé tão grossas como um homem pela cinta; os seus ramos são as mesmas folhas arrumadas como as da palmeiras; e cria-se o fruto no tronco entre as folhas."

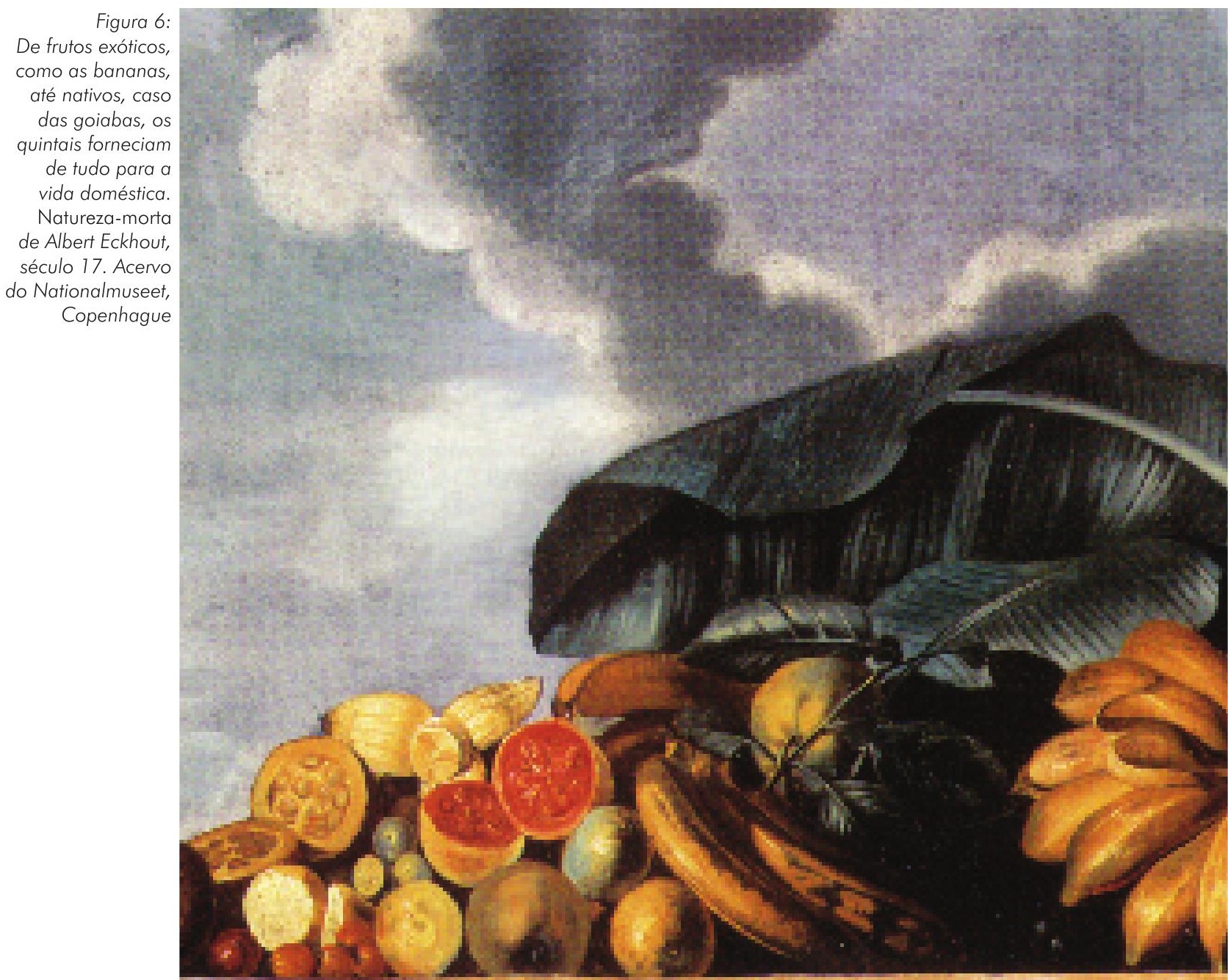




\section{Essências da Terra}

Gabriel Soares de Sousa se atém às fruteiras autóctones muito mais que os cronistas anteriores, servindo-se do mesmo tipo de análise comparativa largamente utilizada na época, que buscava explicar o desconhecido a partir das espécies então comuns e difundidas na Europa. Entre vários exemplos, citava três que se tornaram recorrentes nos quintais baianos e nordestinos: as mangabeiras, as goiabeiras e os maracujazeiros. Refere-se às primeiras como tendo porte semelhante aos pessegueiros, "troncos delgados, e a folha miúda, e a flor como a do marmeleiro; o fruto é amarelo corado de vermelho, como pêssegos calvos, ao qual chamam mangabas" (SOUSA, 2000, p. 151).

As goiabeiras são comparadas às macieiras "na grandura, na cor da casca, no cheiro da folha e na cor e feição dela. A flor é branca, da feição da de murta, e cheira muito bem. Ao fruto chamam araçás [nome mais corrente para as goiabas na época], que são da feição das nêsperas, mas alguns muito maiores. (...) Esta fruta se come toda, e tem ponta de azedo muito saboroso, da qual se faz marmelada" (SOUSA, 2000, p. 155-6).

Os maracujazeiros são inicialmente descritos por sua capacidade de gerar boa sombra nos quintas: apresentam "rama como hera e tem a folha da mesma feição, a qual atrepa pelas árvores e as cobre todas, do que se fazem nos quintais ramadas muito frescas, porque duram, sem secar, muitos anos". E tudo o mais que produzia tinha emprego: "a folha da erva é muito fria e boa para desafogar, pondo-se em cima de qualquer nascida ou raga (...) nascem umas frutas como laranjas pequenas, muito lisas por fora; a casca é da grossura da das laranjas de cor verde-clara, e tudo o que tem dentro se come, que além de ter bom cheiro tem suave sabor" (SOUSA, 2000, p. 160).

\section{Ampliação da Lista}

No século 17, o aparecimento de mais obras revelava a ampliação do repertório de plantas alimentares aclimatadas ou descobertas no próprio Brasil e de sua presença, simultaneamente, em vários casos, em diversas regiões da colônia.

Realizada entre 1625 e 1631 por frei Cristóvão de Lisboa (1583-1652), a História dos animais e árvores do Maranhão relacionava as principais plantas úteis naquela capitania e possivelmente freqüentes nos quintais locais. Pela primeira vez, apresentava ilustrações de 55 espécies vegetais, especialmente autóctones, acompanhadas de sucintas informações escritas sobre seu aspecto e aproveitamento.

Entretanto, o principal trabalho seiscentista que reuniu boa parte do conhecimento escrito e visual disponível sobre vegetação econômica no Brasil foi 
realizado por Georg Marcgrave (1610-44) e outros. Editada em 1648, a História natural do Brasil trazia um rico apanhado, principalmente, de plantas nativas de Pernambuco e do Nordeste do Brasil, concentradas nos três primeiros de seus oito volumes. Entre árvores, arbustos e herbáceas para emprego alimentar, medicinal e na produção de artefatos, relacionava 232 espécies, ilustradas por xilogravuras feitas a partir de desenhos de Albert Eckhout (161065). Apresentava mais algumas fruteiras nativas que, provavelmente, já faziam parte dos quintais domésticos, mas não incluídas constantemente em estudos anteriores, como as jabuticabeiras.

\section{Retratos da Diversidade}

pintor Albert Eckhout foi responsável pelo melhor registro visual de herbáceas e arbustos úteis, árvores frutíferas, frutas, legumes, hortaliças e tubérculos, empreendido nos dois primeiros séculos da colonização. Como nenhum artista anterior, retratou a diversidade de espécies nativas e exóticas que ambientavam os exteriores da casa brasileira. Concebeu uma das primeiras imagens de um quintal doméstico rural, lançando-o como pano de fundo do quadro Mulher Tupi. Nele se vê o quintal da típica casa-grande nordestina, cercado por muros, ladeado por aléias de fruteiras e servindo para a criação de animais.

\section{Jóias Orientais}

Entre as últimas introduções vegetais realizadas pelos portugueses, em fins do século 17, estavam duas jóias da natureza oriental: as jaqueiras e as mangueiras.

As jaqueiras provêm da Índia, de onde foram levadas pelos lusitanos para - Ocidente. Em 1682, algumas mudas remetidas de Goa foram plantadas na Bahia e, tempos depois, já havia 11 pés "crescidos e viçosos" em terras baianas, segundo Francisco Lamberto (apud ALMEIDA, 1975, p. 383). No ano seguinte, nova remessa seguiu para o Brasil, com sete tinas de madeira com jaqueiras, e 18, com pimenteiras, caneleiras e mangueiras, sendo parte delas perdidas no caminho (apud ALMEIDA, 1975, p. 383). Da Bahia, as jaqueiras foram espalhadas pela faixa tropical da colônia, conquistando popularidade, por exemplo, no Rio de Janeiro dos séculos 18 e 19.

Também originária da Ásia, da região entre Índia e Birmânia, as mangueiras chegaram às mãos dos portugueses nas Ilhas Molucas, no início do século 16. No final do século seguinte, já estavam na costa ocidental da África e Brasil (FERRÃO, 1993, p. 186-8), alcançando grande difusão nos quintais de localidades quentes, tempos depois. 


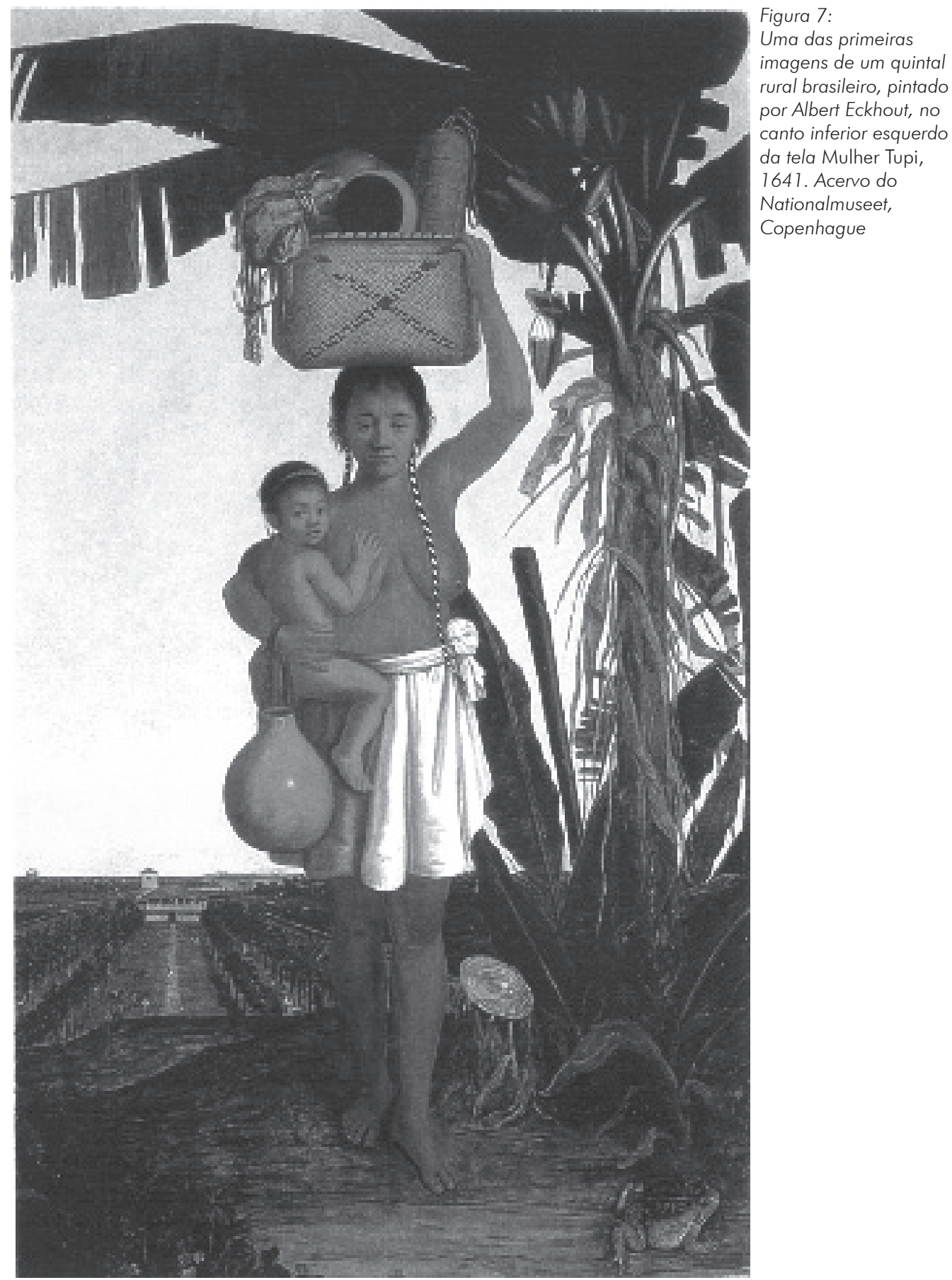

Os dois primeiros séculos da colonização foram cruciais para a formação dos quintais domésticos no Brasil. Época de intensos e profundos intercâmbios culturais, que determinaram as feições típicas das áreas externas da casa colonial. Momento em que grande parte das espécies vegetais foi introduzida e passou a figurar como marca registrada desses ambientes tão caros à vida e memória coletiva brasileira. 


\section{Bibliografia}

ALBUQUERQUE, Antonio Luiz Porto e. Os descobrimentos portugueses e o encontro de civilizações. Rio de Janeiro: Nórdica, 1999.

ALGRANTI, Leila Mezan. Famílias e vida doméstica. In: SOUZA, Laura de Mello e (Org.). Cotidiano e vida privada na América Portuguesa. História da vida privada no Brasil. São Paulo: Companhia das Letras, v. 1, 1997. (Cap. 3).

ALMEIDA, Luís Ferrand de. Aclimatação de plantas do Oriente no Brasil durante os séculos XVII e XVIII. Revista Portuguesa de História. Coimbra, v. 15, p. 339-481, 1975.

ASSUNÇÃO, Paulo de. A terra dos Brasis: A natureza da América portuguesa vista pelos primeiros jesuítas (1549-1596). São Paulo: Annablume, 2000.

BARLÉU, Gaspar. História dos feitos recentemente praticados durante oito anos no Brasil. Belo Horizonte: Itatiaia, 1974.

BERLOWICZ, Bárbara et al. (Ed.). Albert Eckhout Volta ao Brasil 1644-2002. Copenhague: Nationalmusseet. 2002.

BOXER, Charles R. O império marítimo português 1415-1825. São Paulo: Companhia das Letras, 2002.

BRANDÃO, Ambrósio Fernandes. Diálogos das grandezas do Brasil. Recife: Fundação Joaquim Nabuco/Editora Massangana, 1997.

CASCUDO, Luís da Câmara. História da alimentação no Brasil. Belo horizonte: Itatiaia, 1983.

CAVAlCANTE, Paulo B. Frutas comestíveis da Amazônia. Belém: CNPq/ Museu Paraense Emílio Goeldi. 1996.

CORONA, Eduardo; LEMOS, Carlos A. C. Dicionário da arquitetura brasileira. São Paulo: Edart. 1972.

CROSBY, Alfred W. Imperialismo ecológico. A expansão biológica da Europa $900-$ 1900. São Paulo: Companhia das Letras, 1993.

DIAMOND, Jared. Armas, germes e aço. Rio de Janeiro/São Paulo: Record, 2001.

FERRÃO, José E. Mendes. A aventura das plantas e os descobrimentos portugueses. Lisboa: Instituto de Investigação Científica Tropical/Comissão Nacional para as Comemorações dos Descobrimentos Portugueses/Fundação José Berardo, 1993.

FLANDRIN, Jean-Louis; MONTANARI, Massimo. História da alimentação. São Paulo: Estação Liberdade, 1998.

FREYRE, Gilberto. Casa-grande e senzala. Formação da família brasileira sob o regime de economia patriarcal. Rio de Janeiro, São Paulo: Livraria José Olympio, 1950.

. Sobrados e mocambos. Decadência do patriarcado rural e desenvolvimento do urbano. Rio de Janeiro: Livraria José Olympio, 1997.

GERBI, Antonello. La naturaleza de las Indias nuevas. De Crsitóbal Colón a Gonzalo Fernández de Oviedo. México D. F.: Fondo de Cultura Económica, 1992. 
GOMES, Geraldo. Engenho e arquitetura. Tipologia dos edifícios dos antigos engenhos de açúcar de Pernambuco. Recife: Fundação Gilberto Freyre, 1998.

GONÇALVES DE MELLO, José Antônio. Tempo dos flamengos. Influência da ocupação holandesa na vida e na cultura do Norte do Brasil. Recife: Banco do Nordeste do Brasil, 1979.

HOEHNE, F. C. Botânica e agricultura no Brasil no século XVI. São Paulo: Companhia Editora Nacional, 1937.

HOUAISS, Antônio; VILLAR, Mauro de Salles. Dicionário Houaiss da Língua Portuguesa. Rio de Janeiro: Editora Objetiva, 2001.

LAPA, José Roberto do Amaral. $\bigcirc$ Brasil e as drogas do Oriente. Studia. Lisboa, n. 18, p. 7-40, ago. 1966.

LEMOS, Carlos A. C. Arquitetura brasileira. São Paulo: Melhoramentos, 1979. . Casa paulista. São Paulo: Edusp, 1999.

. Cozinhas, etc. Um estudo sobre as zonas de serviço da casa paulista.

São Paulo: Perspectiva, 1976.

LISBOA, Cristóvão de. História dos animais e árvores do Maranhão. Rio de Janeiro: Editorial Alhambra, 1985.

MARCGRAVE, Jorge; PIZO, Wilhem. História natural do Brasil. São Paulo: Imprensa Oficial do Estado, 1942.

MARX, Murillo. Cidade brasileira. São Paulo: Melhoramentos/Editora da Universidade de São Paulo, 1980.

MELLO, Evaldo Cabral de. À sombra dos coqueirais. Folha de S. Paulo, São Paulo, 4 abr. 1999. Caderno Mais.

MENESES, José Newton Coelho. Continente rústico. Abastecimento alimentar nas Minas Gerais setecentistas. Diamantina: Maria Fumaça, 2000.

MICELI, Paulo. O tesouro dos mapas. A cartografia na formação do Brasil. São Paulo: Instituto Cultural Banco Santos, 2002.

NOGUEIRA, Eliana. Uma história brasileira da botânica. Brasília/São Paulo: Paralelo 15/ Marco Zero, 2000.

PÉREZ, Joaquín Fernández; TASCÓN, Ignacio González. La agricultura viajera. Cultivos y manufacturas de plantas industriales y alimentares en España y en la América Virreinal. Madri: Real Jardín Botânico, s/d.

PRESTES, Maria Elice Brzezinski. A investigação da natureza no Brasil colônia. São Paulo: Annablume/Fapesp, 2000.

RIBEIRO, Marcia Moisés. A ciência dos trópicos. A arte médica no Brasil do século XVIII. São Paulo: Hucitec, 1997.

RITCHIE, Carson I. A. Comida y civilización. De cómo los gustos alimenticios han modificado la historia. Madri: Alianza Editorial, 1996.

SALLES, Paulo. O jardineiro brazileiro. Rio de Janeiro: H. Garnier, 1898.

SEGAWA, Hugo. Ao amor do público. Jardins no Brasil. São Paulo: Studio Nobel/ Fapesp, 1996. 
SILVA, Silvestre. Frutas Brasil frutas. São Paulo: Empresa das Artes, 1991.

SOUSA, Gabriel Soares de. Tratado descritivo do Brasil em 1587. Recife: Fundação Joaquim Nabuco/Editora Massangana, 2000.

TAUNAY, Carlos Augusto. Manual do agricultor brasileiro. São Paulo: Companhia das Letras, 2001.

VAINFAS, Ronaldo (Org.). Dicionário do Brasil Colonial 1500-1808. Rio de Janeiro: Objetiva, 2000.

VAlLADARES, Clarival do Prado; MELLO FILHO, Luiz Emygdio. Presença da Holanda no Brasil - Século XVII. Albert Eckhout. Rio de Janeiro: Edições Alumbramento, 1998.

VRIES, Elly de (Org.). Albert Eckhout volta ao Brasil 1644-2002. In: SIMPÓSIO INTERNACIONAL DE ESPECIALISTAS. Recife: Projeto Albert Eckhout Volta ao Brasil 1644-2002, 2002.

\section{Agradecimento}

Nossos agradecimentos a Miguel Infante (Arquivo Histórico Ultra-marino do IICT, Lisboa), Graça Ramalhinho (Museu Bocage, Universidade de Lisboa), Carlos Lemos, Dante Teixeira Martins, Elly De Vries, Hugo Segawa, Catharina Cordeiro Lima e Fanny Galender. 